\title{
UNA PELÍKE DEL PINTOR DE EUCHARIDES PROCEDENTE DE CABEZO LUCERO (ALICANTE)
}

A PELIKE BY THE EUCHARIDES PAINTER FROM CABEZO LUCERO (ALICANTE)

\author{
MARTÍN ALMAGRO-GORBEA \\ Real Academia de la Historia
}

Recepción: 14-05-2009; Aceptación: 09-09-2009

El estudio del lékythos de Pozo Moro (Almagro-Gorbea, 1983, lám. 15) ha requerido un análisis de los productos similares aparecidos en la Península Ibérica que nos ha llevado a identificar un interesante vaso atribuible al Pintor de Eucharides en la bien conocida necrópolis ibérica de Cabezo Lucero, situada en Guardamar de Segura, Alicante (Aranegui et alii, 1993), pieza que, a pesar de su interés, había pasado desapercibida.

La necrópolis ibérica de Cabezo Lucero controla la estratégica desembocadura del río Segura, a unos $2 \mathrm{~km}$ del yacimiento fenicio de La Fonteta (González Prats, 1998; González Prats et alii, 1999; Rouillard et alii, 2007), del que debe considerarse su contrapartida indígena.

Las excavaciones llevadas a cabo en esta característica necrópolis ibérica han permitido recuperar un interesante conjunto de cerámicas áticas, que fueron en su día estudiadas por P. Rouillard (1993), quien también las valoró en su tesis doctoral, publicada poco antes (Rouillard, 1991), y que por su interés han merecido

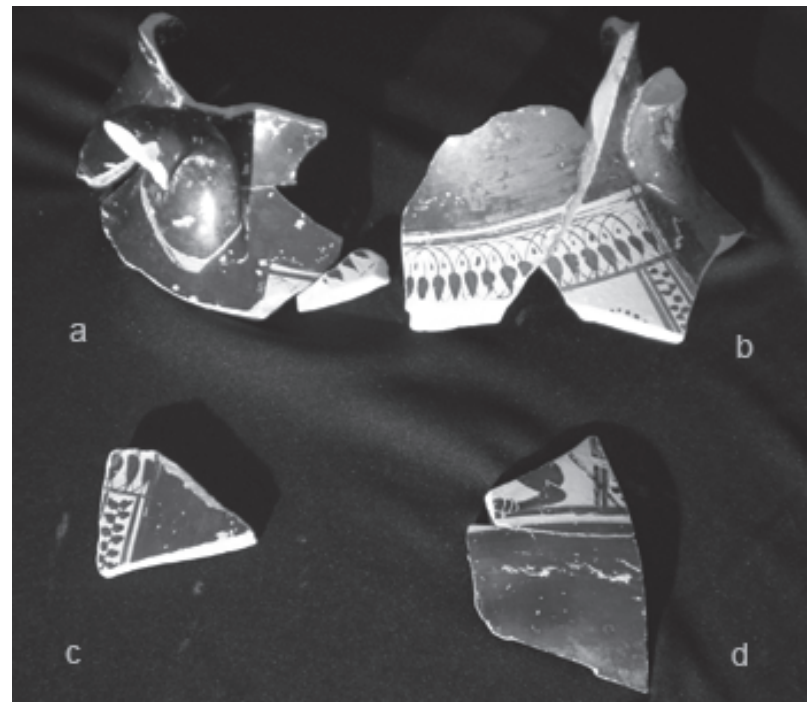

Figura 1: Fragmentos de una pelike del Pintor de Eucharides procedente de Cabezo Lucero. la atención de diversos investigadores (Shefton, 1990; Shefton, 1995; Domínguez Monedero y Sánchez, 2001; Fless, 2000, 170 s.).

Sin embargo, entre los 696 fragmentos de cerámica ática recuperados (Rouillard, 1993, 88, tabla A), han pasado desapercibidos 10 fragmentos de una pelike de figuras negras de indudable interés, al parecer interpretados como de pelikai de figuras rojas, de los que se habían identificado 5 piezas (Fig. 1), que deben corresponder a estos fragmentos (Rouillard, 1993, 90). Sin embargo, aunque únicamente se conserva menos del $10 \%$ del vaso y sólo una pequeña parte de las cenefas del contorno del panel decorativo, éstas son muy características y fueron en particular utilizadas en obras del Pintor de Eucharides, lo que permite identificar al autor del vaso con suficiente seguridad.

Los 5 fragmentos publicados (Fig. 1) fueron recogidos con el $\mathrm{n}^{\circ}$ A 111 como procedentes del 'Punto 29', pero junto a ellos aparecieron otros que han pasado desapercibidos en el estudio de los materiales y del yacimiento a pesar de su importancia, pues fueron atribuidos por error a un vaso de figuras rojas, que se fechó c. 400 a.C., tal como indica la publicación de la necrópolis (Aranegui et alii, 1993, 190, lám. 76): «-A 111. Pélice. Se conservan partes del marco de una de las caras: arriba, guirnalda de capullos de flores de loto, rodeada de puntos; sobre el lateral, cadena de puntos entre dos líneas verticales. En el ángulo dcho. de la cara A: parte de un círculo de puntos que podría corresponder a la parte superior de un tirso a la altura del arranque del asa. Hacia el 400 a.C. Lám. 79.». Domínguez Monedero y Sánchez (2001) no los recogen, pero sí Fless $\left(2000,171\right.$, n. $\left.6^{1}\right)$ en su estudio de las cerámicas áticas del siglo IV a.C.

1. Pelike: Cabezo Lucero 190A 111 lám. 79; Cabezo Lucero 191 A 41, fig. 33,4, lám. 82, 83; Cabezo Lucero 270 s., A23, lám. 101; Cabezo Lucero 275 A 4; Cabezo Lucero 276, A 24, lám. 103. 
A este mismo vaso se debe atribuir otro fragmento publicado procedente del área A2-B2 (Fig. 1,d), en la que se incluye el 'Punto 29' de donde proceden los fragmentos anteriores (Aranegui et alii, 1993, planos p. 20, 22, 25, 26), que se describe del modo siguiente: «-A 169. Parte inferior de la panza de un vaso cerrado: parte dcha. de un panel; piernas dobladas de un animal de perfil hacia la izq.; encima línea oblicua. A: $8,7 \mathrm{~cm}$. L: $5,5 \mathrm{~cm}$. Fin siglo VI - principio siglo V a.C. Lám. 106.» (Aranegui et alii, 1993, 282, lám. 106), fragmento que también recogen sin más comentario Domínguez Monedero y Sánchez $(2001,42)$.

El análisis de los fragmentos (Fig. 1,a-b) permite comprobar que el 1,a (2 fragmentos) y el 1,b (3 fragmentos) corresponden a los dos ángulos, derecho e izquierdo, de la cenefa superior de una de las caras de la pelike con el arranque de las dos asas del vaso, mientras que el fragmento 1,c, más pequeño, corresponde al ángulo superior derecho del panel decorativo, por lo que debe pertenecer a la otra cara. Además, se conserva otro fragmento del cuello no publicado, relativamente amplio, que pega con los fragmentos $1, \mathrm{~b}$ y permite apreciar que por el interior el barniz se extendía hasta $2,5 \mathrm{~cm}$ por encima del panel decorativo, quedando todo el interior sin barniz. Igualmente, se conserva otro pequeño fragmento no publicado de la cenefa de capullos de loto, que constituye el enlace entre los fragmentos 1 , a y $1, \mathrm{~b}$, lo que permite completar prácticamente toda la cenefa superior de una de las caras de la pelike, lo que ayuda a reconstruir sus dimensiones y su forma (Fig. 2).

Por desgracia, del campo decorativo apenas se conserva en el fragmento $1, b$ una característica línea de puntos que cabe interpretar como una hilera de hiedra de las que adornan el campo de los vasos de figuras negras tardías decorados con escenas dionisíacas (Fig. 3), aunque en el Pintor de Eucharides más bien pudiera tratarse de una corona de hiedra como la que suele llevar alguno de los personajes por él pintados (Fig. 5,a-b, 6,a, 7, 8,a-b y 10). También el fragmento 106 pertenece al mismo vaso, pues corresponde al ángulo inferior derecho del panel decorativo de esta pelike de figuras negras y ofrece las patas traseras de un animal, probablemente un perro, gato, pantera o similar, sentado hacia la izquierda. A juzgar por la forma

Los fragmentos se conservan en el Museo Arqueológico de Alicante con el $\mathrm{n}^{\circ}$ de referencia: CL 86-I B2 A111, n 1333 y CL 81-I $n^{\circ} 1337$. Conste nuestro agradecimiento al D. Manuel Olcina Doménech, Director Técnico del Museo Arqueológico de Alicante y a Dña. Consuelo Roca de Togores, Conservadora del mismo, por la tan eficaz ayuda prestada para estudiar estos fragmentos. De forma especial, quiero agradecer a Dña. $\mathrm{M}^{\mathrm{a}}$ Dolores Sánchez del Prado el dibujo de los fragmentos y la reconstrucción de la pelike.

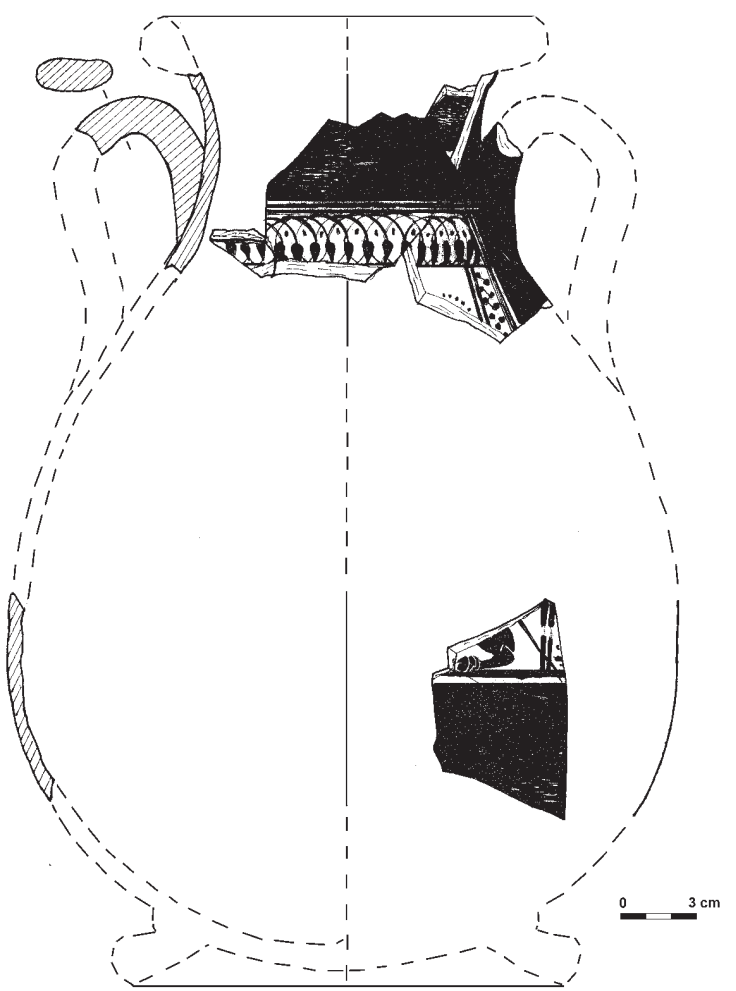

Figura 2: Perfil reconstruido de la pelike de Cabezo Lucero (reconstrucción $\mathrm{M}^{\mathrm{a}} \mathrm{D}$. Sánchez de Prado).

de pintar la cenefa, pertenece a la misma cara que los fragmentos $1, \mathrm{a}$ y $1, \mathrm{~b}$, por lo que dicha cara ofrecería una escena con un animal en su ángulo inferior izquierdo, quizás una pantera o un perro, sentado hacia la izquierda, probablemente ante un hombre apoyado en un largo bastón, que parece pasar por encima o por detrás del animal y que atraviesa la cenefa lateral de puntos alternos (Fig. 1,d), mientras que en la parte superior, en el ángulo superior izquierdo del panel decorativo, se observan los puntos de lo que parece ser la corona de hiedra de la cabeza de dicho personaje.

El barniz de esta pelike es negro uniforme de buena calidad y está extendido a torno con el pincel, salvo en las asas, cuya parte inferior no llega a estar barnizada. El interior aparece barnizado en la boca y el cuello hasta $25 \mathrm{~mm}$ por encima de la cenefa superior del panel decorativo, quedando todo el interior sin barnizar. Las paredes son lisas, pero en el interior se observan con claridad las huellas del torno, en especial en la parte inferior del vaso.

Dimensiones: Altura teórica: c. $38 \mathrm{~cm}$. Diámetro máximo teórico: c. $30 \mathrm{~cm}$. Diámetro teórico de la boca: c. $15 \mathrm{~cm}$. Diámetro del cuello: $11,5 \mathrm{~cm}$. Grosor máximo (debajo de las asas): $8 \mathrm{~mm}$. Grosor mínimo (zona inferior bajo la esfinge): $5 \mathrm{~mm}$. (Figs. 1-2).

La combinación de cenefas que presenta esta $p e-$ like, una superior formada por capullos de loto inverti- 
dos con puntos en los espacios intermedios y dos laterales con sendas cadenas de puntos alternos entre dos líneas verticales resulta muy característica, pues son relativamente raras las piezas que la ofrecen y aún son más raras en pelíkai, lo que facilita la identificación de su taller y permite plantear su relación con el Pintor de Eucharides, atribución que confirma la semejanza de la pata del perro o pantera sentado (Fig. 1,d) con la de una esfinge en la misma actitud (Fig. 4,a) de la pelíke de la Universidad de Chicago (Price, 1971, lám. 93, fig. 2; Berge, 1980, $\left.\mathrm{n}^{\circ} 79, \mathrm{~A}\right)$, pues ambas ofrecen la pata levantada a pesar de estar el animal sentado.

La pelike es un vaso derivado del ánfora y con sus mismas funciones, aunque de panza más baja y gruesa (Richter y Milne, 1935: 4-5); en concreto, se considera derivada del ánfora de tipo $\mathrm{C}$ hacia el 520 a.C. y se usaba en especial para contener aceite (Shapiro, 1997: 63). Por lo tanto, la introducción de este forma en la cerámica ática fue tardía, en el último cuarto del siglo VI a.C., cuando ya se desarrollaba la técnica de figuras rojas. Además, es una forma que nunca fue muy frecuente, en especial las decoradas con figuras negras, pues sólo se conoce un centenar de éstas (ibidem; von Bothmer, 1979, 361), aunque ganó popularidad paulatinamente entre los vasos de figuras rojas hasta el siglo IV a.C.

En un artículo muy esclarecedor que seguía recopilaciones anteriores como las de Mingazzini (1930, 275) y Johnson (1943, 395), D. von Bothmer (1951) llamó hace más de 50 años la atención sobre el interés de las pelíkai de figuras negras y ofreció una primera aproximación al análisis de las cenefas que encuadran su panel decorativo.

D. von Bothmer (1951), en los 70 ejemplares por él reunidos con el apoyo de J. D. Beazley, lo que da idea de la relativa rareza de esta forma, que ha llevado a ser excluida de algunos índices de búsqueda del Corpus Vasorum Antiquorum (Carpenter y Mannack, 2000, 83 s.), distinguió hasta 16 tipos de cenefas para enmarcar el panel figurado realizadas por combinación de apenas seis motivos, elemento tomado de las ánforas 'de panel', de las que parece derivar la forma de la pelike $\mathrm{y}$, en cualquier caso, su sistema decorativo.

Las primera consiste en una cenefa de capullos de loto enlazados situada en la parte superior y otra cenefa de meandros en la parte inferior con series de puntos alternos a los lados $\left(\mathrm{n}^{\circ} 1\right)$, combinación utilizada por el Pintor Nikoxenos, quien también asoció la cenefa de lotos enlazados en la cenefa superior a puntos alternos en la inferior ( $\mathrm{n}^{\circ} 3$ a 5), mientras que la cenefa de capullos de loto en la parte superior combinada con otra cenefa de meandros en la parte inferior fue utilizado por el Pintor de Aqueloo ( ${ }^{\circ}$ 2).

El grupo siguiente ofrece la cenefa de capullos de loto enlazados en la parte superior y las series de puntos alternos a los lados, sistema que parece haber utilizado la pelike de Cabezo Lucero. D. von Bothmer (1951, n 6 a 12) integró 7 piezas en este grupo, cuya numeración y descripción seguimos (vid. infra, $\mathrm{n}^{\circ} 6$ a 12), de las que al menos 5 de ellas ( $n^{\circ} 6$ a 10) son del Pintor de Eucharides y a las que se puede añadir la de Cabezo Lucero y alguna pieza más dada a conocer posteriormente.

Más frecuente resulta el uso de una cenefa de lotos sólo en la parte superior ( $\mathrm{n}^{\circ} 12$ a 23), utilizada por el Pintor de Aqueloo ( ${ }^{\circ} 13$ y 14 ) y por el Grupo de Leagros (n 18) y, quizás también por el Pintor de Eucharides (vid. infra, $\mathrm{n}^{\circ} 12$ ); puntos alternos en la parte superior y en los laterales ( ${ }^{\circ} 24$ a 27), como emplea el Pintor de Teseo ( ${ }^{\circ} 25$ y 26); puntos alternos sólo en la parte superior (n ${ }^{\circ} 29$ a 36), sistema usado por el Grupo de la Pelike de Rodas ( ${ }^{\circ} 30$ y 34 ), por el de Rodas 10775 o el de Atenas 581 ( $\left.\mathrm{n}^{\circ} 33\right)$ y por el Pintor de la Línea Roja o Red-line Painter ( ${ }^{\circ} 31$ ), que igualmente cabe incluir como representantes finales del Grupo de Leagros. También aparece asociada la cenefa de series de puntos alternos a palmetas en la parte superior $\left(\mathrm{n}^{\circ}\right.$ 37) y a hojas de hiedra ( $\mathrm{n}^{\circ} 49$ a 52bis) y a hojas de mirto ( $\left.\mathrm{n}^{\circ} 53-54\right)$. Igualmente, la cenefa de puntos puede aparecer en una cara alternando en la otra con una cenefa de palmetas ( $\mathrm{n}^{\circ} 55$ y 55bis), éste último sistema utilizado por el Red-line Painter. Los restantes sistemas decorativos identificados consisten en una cenefa de palmetas en la parte superior $\left(n^{\circ} 38\right.$ a 43), usado por el Pintor de Aqueloo ( ${ }^{\circ} 38$ y 40), meandros en la parte superior ( $\mathrm{n}^{\circ} 44$ a 48bis), meandros en una cara y hojas de hiedra en la otra ( ${ }^{\circ} 56$ a 59), utilizado también por el Grupo de la Pelike de Rodas ( $\left.{ }^{\circ} 56\right)$, mientras que otra serie de pelíkai carecen de cenefa decorativa $\left(\mathrm{n}^{\circ}\right.$ 60 a 62) o se trata de fragmentos que no permiten identificar las combinaciones del sistema decorativo $\left(\mathrm{n}^{\circ} 63\right.$ a 71).

El Pintor de Andokides fue quien introdujo la idea de enmarcar el panel de las ánforas de tipo A entre una cenefa de palmetas arriba, otra de lotos abajo y un pequeño borde de puntos alternos a los lados, como documenta el ánfora de Boston (Boardman, 1975, fig. 2; Cohen, 1978, 55 s., lám. 7,2-3). La idea la imitaron sus seguidores, como Euthymides (Boardman, 1975, lám. 33,1; Arias y Hirmer, 1960, lám. 117) y otros pintores tardíos de figuras negras, quienes desarrollaron estas bandas ornamentales del panel, innovaciones que pasaron de las ánforas a las pelikai al crearse esta forma hacia el 520 a.C., proceso en el que Nikoxenos parece haber tenido un destacado papel. A este artista se atribuye la introducción de la cenefa de lotos en la parte superior de la pelike, cuyo éxito evidencia su uso en un tercio de los vasos clasificados por D. von Bothmer (1951, n 1-23). También debió introducir las cenefas laterales de puntos enlazados, documentadas en 17 ejemplares (Bothmer, 1951, nº 1, 6-13, 24-28, 37, 49, 
53, 55bis), que en pelíkai avanzadas se convierten en simples puntos alternos en torno a una línea. Este motivo también se utilizó en la parte inferior en 3 pelíkai (Bothmer, 1951, n 3-5) y en la parte superior del panel en otros 20 casos (Bothmer, 1951, n² 29-36quater, 54, 55bis).

D. von Bothmer (1951) también observó que las distintas combinaciones de cenefas ornamentales permitían identificar a los pintores que las usaron. Los ejemplos señalados por D. von Bothmer (vid. supra) indican que la cenefa de capullos de loto enlazados en la parte superior asociada a series de puntos alternos a los lados fue un sistema decorativo originario de las ánforas de panel implantado en las pelíkai por el Pintor de Nikoxenos, quien también utilizó los lotos en la cenefa superior asociados a puntos alternos en la inferior. Nikoxenos es considerado por Beazley (1913, 245; 1956, 395) el maestro del Pintor de Eucharides, hasta el punto de que apenas se diferencian las obras de figuras negras de uno y otro, hecho que explica que el uso de una cenefa de capullos de loto enlazados en la parte superior combinada con series de puntos alternos a los lados sea el método preferido del Pintor de Eucharides, quien lo adoptó de Nikoxenos.

En consecuencia, el empleo de cenefas de capullos de loto en la parte superior fue característico del taller de Nikoxenos-Eucharides, pues sólo está documentado en otro pintor, el de Aqueloo, que en un caso lo asocia a una cenefa de meandros en la parte inferior (vid. supra, $\mathrm{n}^{\circ} 2$ ) y en otros carece de la característica asociación a las cenefas laterales de puntos (Bothmer, 1951, $\mathrm{n}^{\circ} 13 \mathrm{y}$ 14). Todo ello lleva a concluir que la pelike de Cabezo Lucero se debe atribuir al Pintor de Eucharides o a su círculo inmediato, sin excluir que pudiera ser obra de un imitador de estas cerámicas de figuras negras del final del Grupo de Leagros, ya que no se conserva ninguna de las figuras que decoraban la pelíke y, además, se han planteado dudas sobre las atribuciones de vasos a este pintor (Stähler 1967), aunque han sido rebatidas por M. Robertson (1992, 118 s.). En todo caso, como bien señaló D. von Bothmer (1951), es evidente que el uso de estas cenefas siguió modas, pues en la fase inicial, que corresponden a pintores del Grupo de Leagros, las pelíkai ofrecen en la parte superior lotos enlazados o palmetas, fase en la que hay que situar el ejemplar de Cabezo Lucero.

Las pelikai de figuras negras finalizaron tras unos 40 años de desarrollo con ejemplares pequeños y de pobre dibujo, ya a inicios del siglo V a.C., sustituidos por los de figuras rojas, que prosiguieron con creciente éxito hasta el siglo IV a.C. al alcanzar su máxima popularidad en el periodo de Kertch, que representa el final de la pintura vascular ática.

Esta evolución de las pelíkai áticas permite situar la obra del Pintor de Eucharides, nombre tomado de la inscripción con el nombre del joven al que dedicó dos

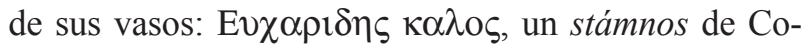
penhague (Beazley, 1912; 1963, 229, n 35) y la hidria del J. Paul Getty Museum no 86.AE.227². Eucharides puede ser considerado como un buen pintor de segunda fila de la generación que estuvo activa entre el $500 \mathrm{y}$ el 470 a.C., en la que es uno de los artistas que mejor supieron compaginar la técnica de figuras negras y de figuras rojas. Su obra fue identificada por J. D. Beazley (1912; 1956, 395 s.; 1963, 226 s., 1637, 1705; 1971, 173 s., 347 s., 510; 1982, 50, 99) y está constituida por vasos de forma muy diversa, entre los que destacan, entre los vasos decorados en figuras negras, las ánforas panatenaicas, las de tipo B (o de panel) y las pelikai y entre los decorados con figuras rojas, ánforas de cuello, panatenaicas y de Nola, cráteras de volutas y de cáliz, hidrias, stámnoi, oinokhóai, pelikai y lékythoi, así como skýphoi y copas, tanto con escenas mitológicas como con escenas de la vida diaria.

Según Beazley, Eucharides habría sido el principal discípulo del pintor Nikoxenos (Beazley, 1912, $228 \mathrm{~s}$; 1913, 245; 1956, 392 s., 395; Robertson, 1992, 120 123). Nikoxenos fue un pintor tardío de figuras negras del Grupo de Leagros (Beazley, 1913; 1928, 24, n. 1; 1956, 392; 1982, 99; Robertson, 1992, 118 s.), ya contemporáneo de los pintores 'pioneros' de figuras rojas, técnica que también llegó a utilizar sin gran fortuna. Según Beazley (1912, 232 s.; 1956, 395 s.; 1963, 228 y 1637; 1971, 347), Eucharides debía trabajar en el mismo taller de Nikoxenos, hasta el punto de que las obras de figuras negras de uno y otro son muy difíciles de distinguir, lo que no ocurre con sus vasos de figuras rojas, que ofrecen estilos diferentes (Beazley, 1912, 228 s.; 1956, 395). Por ello, J. D. Beazley $(1956,395)$ llegó a suponer que las obras del Pintor de Nikoxenos correspondían a la fase inicial del Pintor de Eucharides, idea que desechó posteriormente. Sin embargo, M. Robertson (1962, 312; 1992, 118 s.) ha insistido en la idea inicial de Beazley al plantear que las obras de figuras negras de uno y otro pintor son tan parecidas que ambas deben atribuirse al mismo Pintor de Nikoxenos, que debió proseguir la tradición de figuras negras mientras su discípulo el Pintor de Eucharides se especializaba en pintar vasos de figuras rojas ya mucho más adaptado a este nueva técnica. Aunque esta autorizada opinión de M. Robertson parece lógica y aunque las atribuciones de J. D. Beazley han sido controvertidas (Stähler, 1967), probablemente sin excesivo fundamento $^{3}$, por razones prácticas se siguen atribuyendo al

2.http://www.getty.edu/art/gettyguide/artObjectDetails?art obj $=14083$

3. K. Stähler (1967) redujo los 90 vasos atribuidos al Pintor de Eucharides a 3 seguros, 2 posibles y 2 relacionados, opinión 


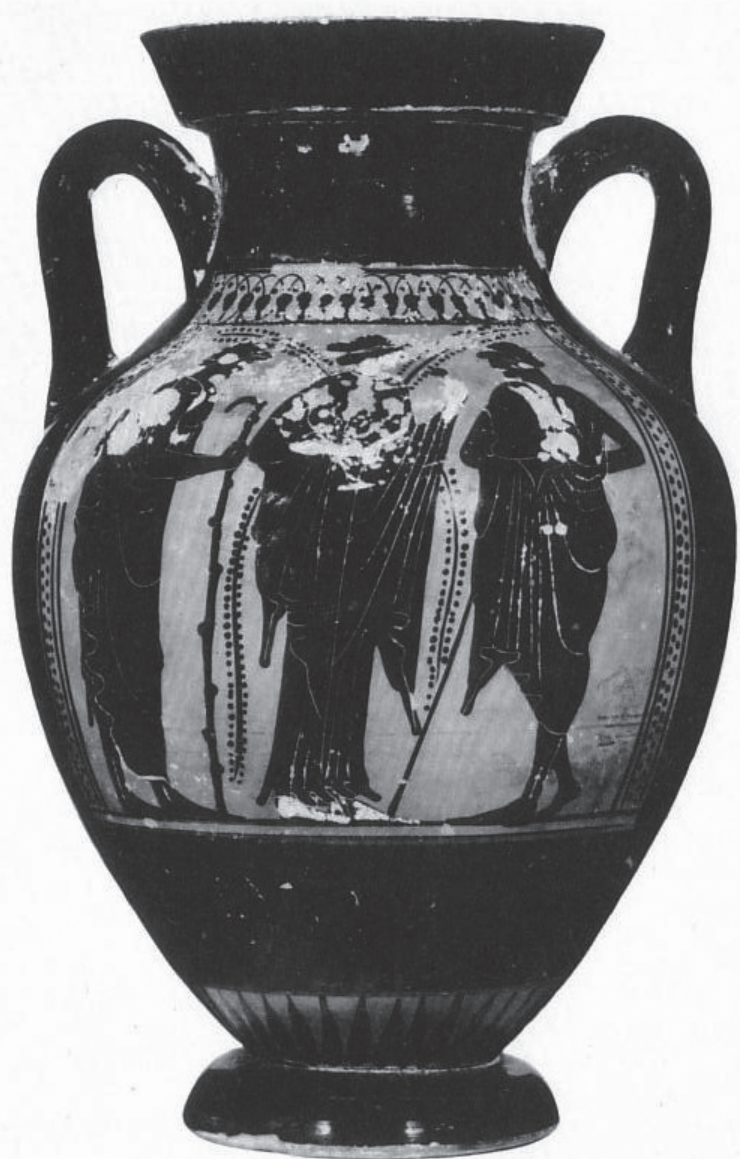

Figura 3: Ánfora del Pintor de Eucharides del Museo de Hamburgo (CVA Hamburg 1, lám. 21,4).

Pintor de Eucharides la producción de figuras negras identificada por Beazley $(1963,395-398 ; 1971,173-$ $174 ; 1982,50)$.

Entre los numerosos vasos de figuras negras del Pintor de Eucharides destacan grandes vasos de forma, como ánforas panatenaicas y de panel, como el que aparece rodeado de cenefas como las que ofrecen las pelikai, como es el caso de las ánforas London B 178 y London 93.7-12 (CVA British Museum 3, lám: 32,3 y 34,3), ambas con las cenefas características, igual que el ánfora del Museo de Hamburgo (CVA Hamburg 1, 33-34, lám. 21,3-4 y 22,3-4), que también se atribuye a la mano de Eucharides según Beazley (1956, 395 s., $696 ; 1971,173)$, a juzgar por su sistema ornamental y el estilo de sus figuras (Fig. 3).

Eucharides pintó pelikai en una proporción relativamente elevada, dada la rareza de esta forma en época arcaica, mucho menos frecuente que las ánforas o hydríai. La lista de pelikai de figuras negras atribuidas al Pintor

hipercrítica rechazada por Robertson $(1962,312)$, aunque es evidente que se trata de obras atribuidas y, por lo tanto, de autoría no segura. de Eucharides por D. von Bothmer (1951) ha sido completada en los Paralipomena y Addenda de J. D. Beazley (1971; 1989) y por R.-M. Becker (1977, 24-30, 106$107 \mathrm{a}, 110)$ y llegan a sumar actualmente 13 ejemplares. Becker recoge 7 pelikai en la 'clase del Pintor Nikoxenos', en la que engloba las siguientes piezas':
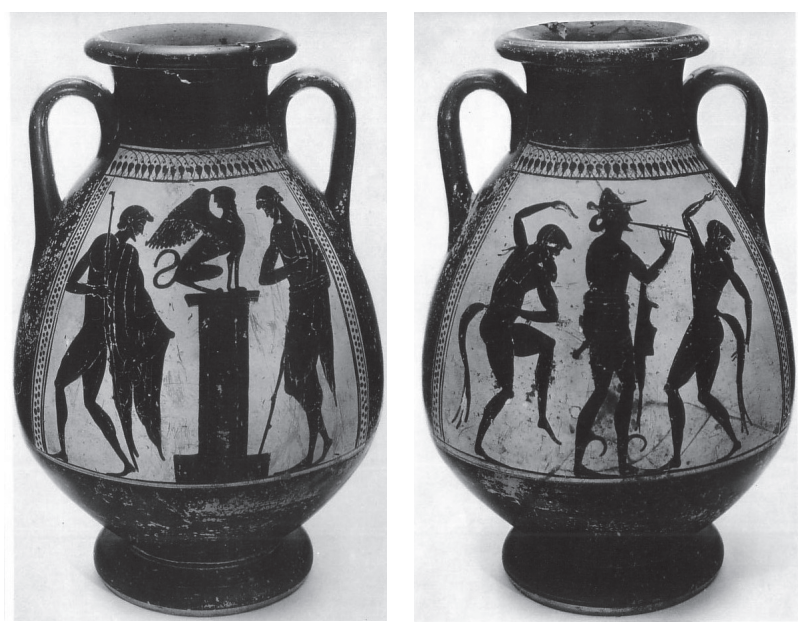

Figura 4: Pelike de Eucharides de la Universidad de Chicago (Berge, 1980).

1) Oxford, Ashmolean Museum G.247/V.563, de Rodas (Fig. 5). $40 \mathrm{~cm}$ de altura. A: Zapatero con joven y personaje con himation; B: Sátiros con Hermes (Beazley, 1956, 396, n² 21; CVA Oxford 2, lám. 8,7-8; Becker, 1977, 9, n 24). c. 490 a.C.

2) San Petersburgo (Fig. 6). Procede de Panticapea (Kertch). Altura desconocida. A: Captura de silenos. B: Mujer entre dos hombres (Pharmakowsky, 1912, 341-342, fig. 25-26; Beazley, 1956, 396, n 24; Bothmer, 1951, n 8; Becker, 1977, 9, lám. 3e y $38 \mathrm{c}, \mathrm{n}^{\circ} 25$ ).

3) Mykonos, de Rheneia. Altura desconocida. A: Venta de aceite. B: Flautista y hombre reclinado (Beazley, 1956, 396, $\mathrm{n}^{\circ}$ 25; Bothmer, 1951, $\mathrm{n}^{\circ}$ 53; Becker, 1977, 9. n²6).

4) Paris, Louvre. $25,3 \mathrm{~cm}$ de altura. A: Sátiros y Hermes (fragmento). (ABV 396, $\mathrm{n}^{\circ} 22$; Bothmer, 1951, n 10; Becker, 1977, 9, lám. 4a y 38d, $\left.n^{\circ} 27\right)$.

5) Boston, Museum of Fine Arts (Fig. 7). $36 \mathrm{~cm}$ de altura. A: Mujer con crótalos entre dos dan-

4. En esta relación no se incluyen las pelíkai del Pintor de Eucharides recogidas por R.-M. Becker (1977) como pelíkai de 'cuerpo pequeño': Richmond, Virginia. $36,5 \mathrm{~cm}$ de altura (Beazley, 1963, 1637,10bis; Stähler, 1967, 32 s., fig. 12b y 13; Becker, 1977, 37, n 106); Münster. $38 \mathrm{~cm}$ de altura. (Stähler, 1967, 32 s., fig. 12d y 42c; Becker, 1977, 37, n 107); Basilea (mercado de antigüedades). $38,1 \mathrm{~cm}$ de altura (Becker, 1977, $\left.38, n^{\circ} 107 a\right)$. 


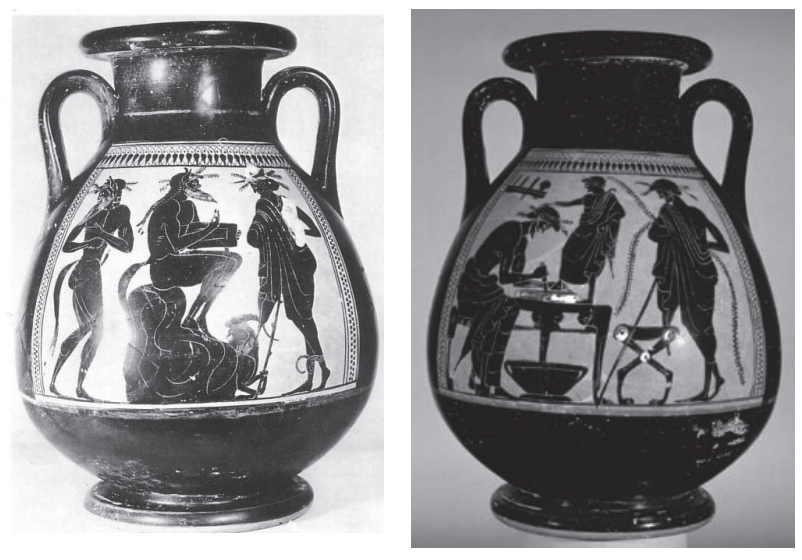

Figura 5: Pelike de Eucharides del Ashmolean Museum de Oxford (v. Bothmer, 1951, lám. 94,1).
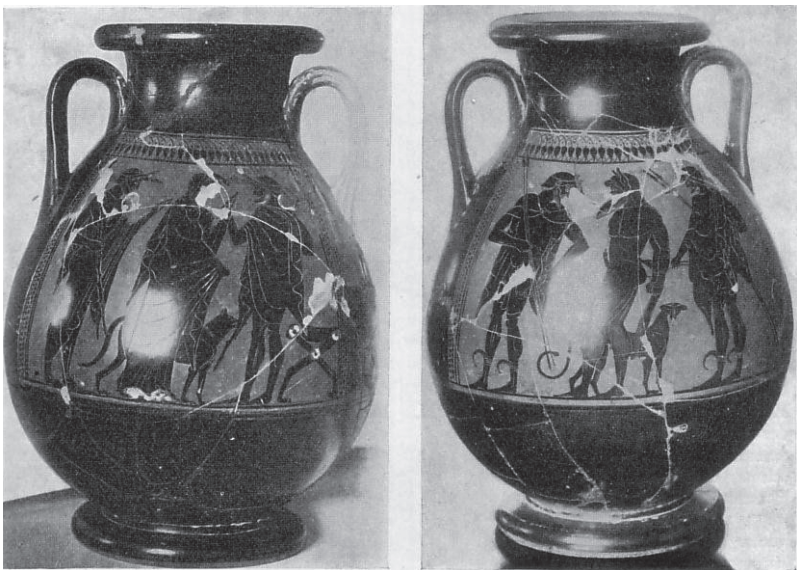

Figura 6: Pelike de Eucharides de Panticapea (Pharmakowsky, 1912, fig. 25-26).

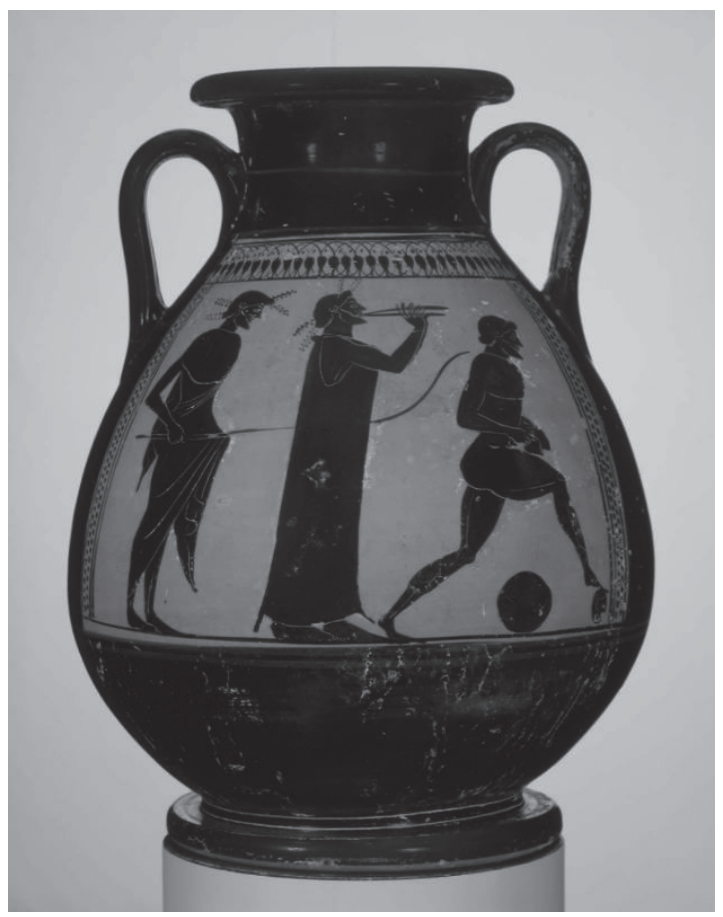

Figura 7: Pelike de Eucharides del Museum of Fine Arts de Boston (www.infa.org. Museum of Fine Arts, Boston). zantes. B: Juez, flautista y saltador entrenándose (Bothmer, 1951, $\mathrm{n}^{\circ}$ 12; Becker, 1977, 9, $\mathrm{n}^{\circ} 28$ ). 500-490 a.C.

6) Chicago, University of Chicago, $n^{\circ} 1967.115 .68$ (Fig. 4). 34,5 cm de altura. A: Hermes tocando la flauta y dos sátiros bailando; B: Dos hombres ante una tumba de pilar rematada en una esfinge. Pintor de Eucharides (Johnson, 1943, 394, fig. 9,A-B; Bothmer, 1951, n 7; Beazley, 1956, 396, $\mathrm{n}^{\circ} 23$ bis; idem, 1971, 60, 17 bis; Price, 1971, 431 s., lám. 93; Becker, 1977, 11, n 30, lám. 4a y 38d, indica 39 cm; Berge, 1980). c. 490 a.C.

7) Samotracia (Fig. 8). 32,6 cm de altura. A: Sátiro, flautista y cabra. B: Citarista y personaje con himation (Beazley 1956, 396, n 23; Lehmann, 1966³, 109, fig. 55; Price, 1971, 432, lám. 94,6-7; Becker, 1977, 10, n²9).
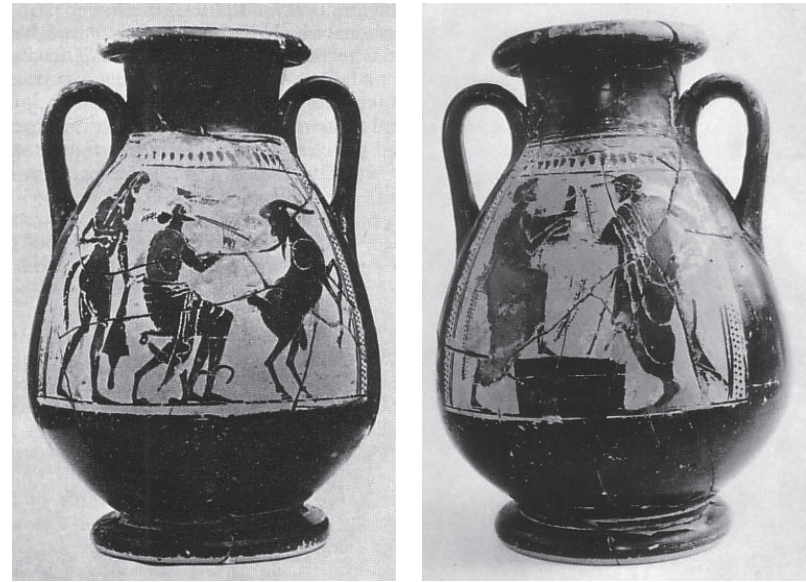

Figura 8: Pelíke de Eucharides de la necrópolis de Samotracia (Price, 1971, lám. 94.7).

A estas siete pelikai que cabe atribuir al Pintor de Eucharides o a su círculo inmediato se debe añadir el de la necrópolis de Cabezo Lucero, actualmente conservado en el Museo de Alicante:

8) Museo de Alicante, de la necrópolis de Cabezo Lucero (Fig. 1,a-d). Fragmentos de la cenefa superior de lotos enlazados con puntos en el campo $\mathrm{y}$ de la lateral con series alternas de puntos $\mathrm{y}$, muy probablemente, del ángulo inferior derecho. Altura desconocida. A: Escena dionisíaca?, con una línea de hiedra estilizada. B?: Escena desconocida, con un animal (pantera o perro?) sentado hacia la izquierda, quizás ante un hombre apoyado en una lanza o un largo bastón (Aranegui et alli, 1993, lám. 79 y 106)5.

5. El cuarto trasero del animal puede compararse al que ofrece la esfinge sobre un pilar en la pelike de la Universidad de Chicago (Price, 1971, lám. 93, fig. 2; Berge, 1980: nº 79,A), escena 


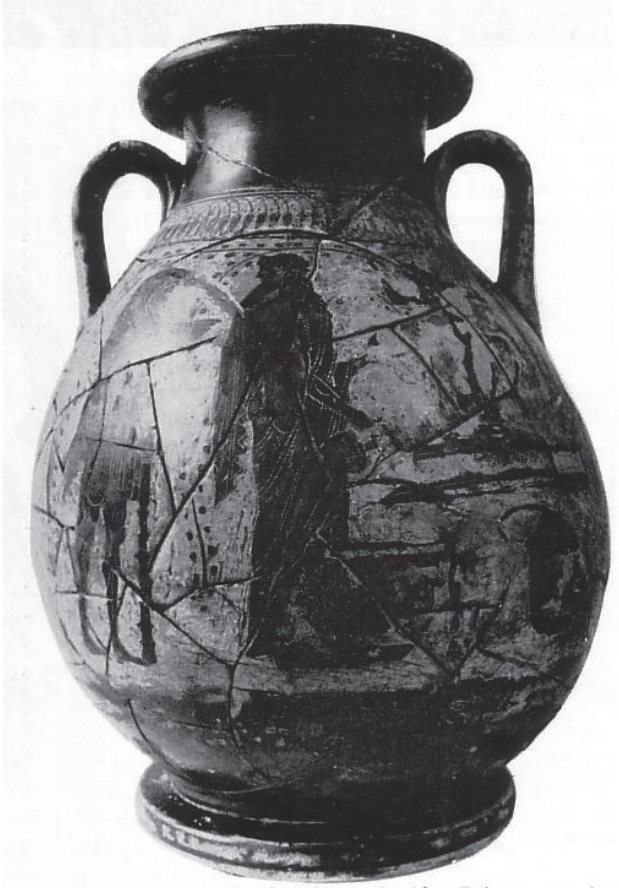

Figura 9: Pelíke de Eucharides de la necrópolis de Samotracia (Dusenbery, 1964, fig 10).

Otra clase de pelíkai de Eucharides serían las de 'cuerpo hinchado' (Aufgebläten Körper), en la que R.M. Becker (1977) incluye un solo ejemplar:

9) Samotracia (Fig. 9). 39,7 cm de altura. A: Escena de prensa y catado de vino con Heracles y Dionisos. B: Sátiros (Dusenbery, 1964a, 191, fig. 10; Becker, $\left.1977,39, \mathrm{n}^{\circ} 110\right)$ c. $500-490$ B.C.

Otras dos pelíkai de las reunidas por D. von Bothmer (1951) entre las de cenefa de lotos enlazados arriba y puntos a los lados ofrece evidente proximidad con el Pintor de Eucharides (vid. supra), por lo que se pueden incluir en esta relación, aunque R.-M. Becker (1977) no las ha tenido en cuenta:

10) Londres, mercado de antigüedades. A y B: Komos. (Bothmer, 1951, n 9, atribuido al Pintor de Eucharides).

11) Viena, SK 258. $28.1 \mathrm{~cm}$ de altura. A: Dionisos entre dos sátiros; B: Mujer entre dos hombres (Laborde, 1813, lám. 30 y 31; Bothmer, 1951, $\left.\mathrm{n}^{\circ} 11\right)$.

Otros dos posibles ejemplares no los recoge D. von Bothmer (1951) ni tampoco R.-M. Becker (1977). Ofrecen sólo la cenefa de lotos enlazados arriba, pues carecen de puntos a los lados, pero su estilo resulta próximo al del Pintor de Eucharides, por lo que se pueden incluir en esta relación:

que también ofrece un personaje apoyado en un largo bastón, actitud que puede considerarse muy habitual en las figuras del Pintor de Eucharides (Price, 1971, lám. 94, fig. 4 y 7; etc.).

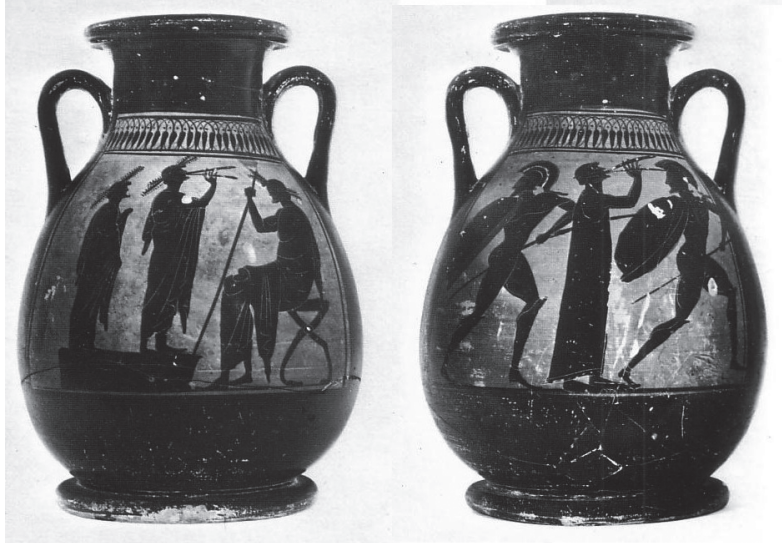

Figura 10: Pelike de Eucharides procedente de Gela (CVA Gela 4, lám. 5,2-3).

12) Siracusa, Museo (Fig. 10). Procedente de Gela. $33 \mathrm{~cm}$ de altura. A: Flautista y cantante; B: Flautista entre dos danzantes pírricos. Carece de bandas laterales de puntos. Atribuido a Eucharides y datado c. 490 a.C (Benndorf, 1883, lám. 43, 4,a-b; Bothmer, 1951, n 15; CVA Gela 4, lám. 5, 2-3; 8 y 9).

13) Missouri. Obra de taller? (Noble, 1965, 80, fig. 246; Price, 1971, 432, n. 126).

14) Florencia, Museo Arqueológico, 72732 (Fig. 11). A: Vendedor de aceite; B: Vendedor de perfumes ante dos perros peleando. Carece de bandas laterales de puntos (Bodiou et alii, 2008: 238, fig. 2; Maffre, 2010: 42). Del Pintor de Eucharides o de un seguidor muy próximo.

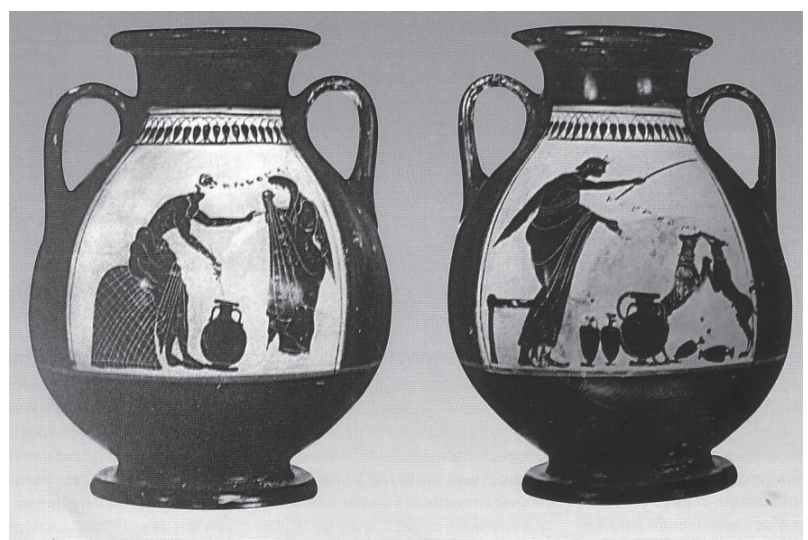

Figura 11: Pelike de Eucharides del Museo Arqueológico de Florencia (Bodiou et alii, 2008, fig. 2).

6. T. H. Price (1971, 432, n. 12) recoge la existencia de esta pelike en Missouri (Noble, 1965, 80, fig. 246, obra no consultada), de inferior calidad y con sólo una doble línea en vez de la cenefa de puntos alternos, que atribuye a un discípulo del taller de Eucharides. 
Esta pelike del pintor de Eucharides hallada en Cabezo Lucero ofrece evidente interés. En primer lugar, plantea el uso más que probable de este vaso como urna funeraria en dicho yacimiento, hecho bien documentado en Grecia (vid. supra, n 2, 3, 7, 9 y 10 del catálogo; Karouzou, 1971, 138-145) y en las colonias griegas del Mar Negro, donde el empleo de este vaso como urna cineraria alcanza el 25\% de las tumbas (Fless, 2000, 84 , n. 726 , lám. 5 y 58 s.), uso que también se ha documentado en alguna tumba ampuritana de cremación (Almagro-Gorbea, 1962), ya que la forma del vaso lo hacían particularmente apto para ello. Además, en el mundo ibérico, aunque las pelíkai son relativamente raras, aparecen en necrópolis, en algunos casos utilizadas igualmente como urna cineraria (Trías, 1968, 120, lám. 214, 215,6, 255, etc.), por lo que ésta pudo ser perfectamente la función de la pelike de Cabezo Lucero, por desgracia hallada en el 'punto 29' fuera de su contexto originario (Aranegui et alii, 1993, 187-190) y, aunque en este yacimiento han aparecido otras cuatro pelikai, su contexto tampoco se precisa en el estudio (Rouillard, 1993, 90; Fless, 2000, 171, n. 6).

Por otra parte, la pelike de Cabezo Lucero amplia el área de aparición de pelikai del Pintor de Eucharides, hasta ahora casi limitada prácticamente al ámbito del Egeo y del Mar Negro, lo que contribuye al mejor conocimiento de la dispersión de los productos de este ceramista. Hasta ahora, en el Mediterráneo Occidental sólo se conocía un ejemplar de figuras negras en Gela (CVA Gela 4, lám. 5,2-3; vid. supra, $\mathrm{n}^{\circ} 15$ ), por lo que su aparición en Cabezo Lucero amplia su presencia hasta Iberia, la zona más remota del mundo conocido en la Antigüedad ${ }^{7}$ (Trías, 1968; Rouillard, 1991; Domínguez Monedero y Sánchez, 2001; Fless, 2000: 41 s.). Además, hay que destacar que esta pelíke puede considerarse uno de los vasos más preciados aparecidos hasta ahora en el ámbito ibérico a fines del siglo VI a.C., ya que en el Sureste y Levante sólo se puede comparar a algunas raras piezas como el lékythos de Liria (Trías, 1968, lám. 157,1-5; Shefton, 1995, 140; Domínguez Monedero y Sánchez, 2001, 51, fig. 44), ya posterior y de menor calidad, y el de Pozo Moro (Fig. 12) (Almagro-Gorbea, 1983, 184, lám. 15,c-d), éste de calidad y fecha muy próximas a la pelike de Cabezo Lucero, pues ambos pertenecen al Grupo de Leagros, si bien el lékythos de Pozo Moro pudiera ser ligeramente anterior, pues parece datarse c. 505-500 a.C., $y$, aunque en principio es un vaso de menor valor, no se debe olvidar su probable contenido de aceite per-

\footnotetext{
7. Al margen de hallazgos 'exóticos' de cerámicas griegas fuera del ámbito mediterráneo y sus zonas de influencia directa, como la copa del Pintor del Pithos hallada en el Támesis (Smith, 2007, 18 s., lám. 14,1-2).
}
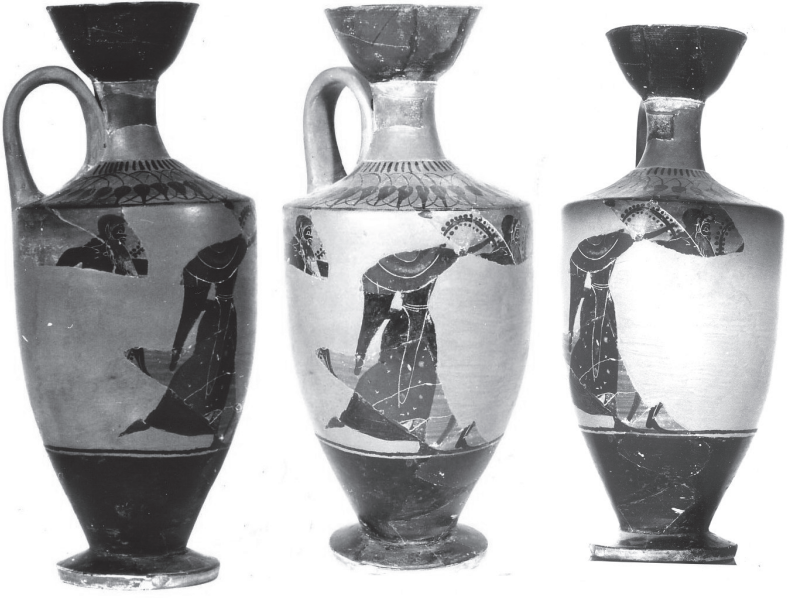

Figura 12: Lékythos ático de la sepultura regia de Pozo Moro, atribuido al Grupo de Leagros.

fumado, que le añadiría valor. Estas señaladas piezas deben relacionarse, a su vez, con los fragmentos de un ánfora de figuras negras hallada en Valencia (Mata y Burriel, 2000, fig. 4,2-4), probablemente atribuible a un pintor del Grupo de Legaros, y con los de una crátera de columnas aparecida en La Albufereta, en Alicante (García Martín y Llopis, 2000), fechada en el último tercio del siglo VI a.C., pero que perfectamente pudiera corresponder a este mismo horizonte de vasos áticos de calidad datados c. 500 a.C.

La pelike de Cabezo Lucero también amplía ligeramente la cronología de los vasos hallados en esta necrópolis, ya que se data con seguridad en el primer decenio del siglo V a.C., quizás incluso hacia el 500 a.C. o 500-490 a.C. con más probabilidad, por lo que sería ligeramente anterior a los otros vasos áticos del yacimiento, tanto de figuras negras (Rouillard, 1993, 87), como de figuras rojas, entre las que destaca la copa C del Pintor del Louvre G 265 (Rouillard, 1991, 556 s.; idem, 1993, 89), de fecha ligeramente posterior, c. 480 a.C., que supone la llegada hasta el ámbito ibérico de una importante obra del círculo del Pintor de Brigos.

Por otra parte, la evidente proximidad entre la pelike de Cabezo Lucero y el lékythos de Pozo Moro, por su estilo, su fecha y su probable iconografía dionisíaca, apunta a una posible llegada común desde Sicilia, lo que aclara las dudas en su día planteadas por Shefton (1995, 148, n. 14 bis) sobre el origen del excepcional ajuar de Pozo Moro a través del comercio ampuritano, quizás ante la anómala variedad y riqueza que ofrece el ajuar de esta sepultura monumental (Almagro-Gorbea, 2009, 20). Por otra parte, el lékythos de Pozo Moro estaba decorado con dos sátiros y ménades y la pelike de Cabezo Lucero ofrece una hilera de hojas de hiedra como las que adornan el campo o las cabezas de los personajes, lo que indica que ambos vasos ofrecían escenas dionisíacas. Este tipo de escenas y las de baile 
son habituales en las pelikai del Pintor de Eucharides (vid. supra), pero también la kýlix de Pozo Moro, de la misma fecha, ofrece un comasta en actitud de danzar oklásma y jugar al kóttabos (Almagro-Gorbea, 2009, 20), asociado, probablemente al simbolismo de la rueda (Deonna, 1953, 83 s., 113 s.) y a ritos dionisíacos.

En consecuencia, todos estos vasos de relativa calidad evidencian la introducción de creencias dionisíacas desde el siglo VI a. C. en las élites sociales ibéricas (Olmos y Sánchez, 1995, 113 s.), como confirma la vajilla de bronce asociada al banquete (Graells, 2008a, 157 s.; 2008b), proceso que anuncia y luego prosigue en las importaciones de cerámicas áticas a partir de fines del siglo V y en el IV a.C. (Villanueva, 1987; Olmos y Sánchez, 1995, 123 s.). Por ello, la introducción del culto dionisíaco en Iberia resulta poco posterior a la de Etruria (Werner, 2005, 75) y, probablemente, contemporánea o incluso algo anterior a la de Roma (Daremberg y Saglio, 1877, 636 s.), donde el culto a Dionisos como Liber Pater se introdujo de manera oficial el 496 a.C. (Bruhl, 1953, 13 s.) por indicación de los Libros Sibilinos, según refieren las fuentes escritas (Dion. Hal. VI, 17; Tac. ann. II,49), esto es, aproximadamente en esos mismos años.

Aunque todavía no se conoce bien cómo y cuando asimiló el mundo ibérico dichas creencias de origen helénico, sin duda deben considerarse asociadas al mundo orgiástico y erótico, que documentan en el Sureste desde la generación del 525 a.C. el sátiro del Llano de la Consolación (García Bellido, 1948, 91 s., lám. 26; Olmos, 1977; Shefton, 1982, 362, n. 69; Rouillard, 1997, 186, n 296), una generación después, la pelike de Cabezo Lucero y la hierogamia del monumento de Pozo Moro (Almagro-Gorbea, 1983, 204, lám. 26; López Pardo, 2006, 96 s.) y en la generación siguiente, ya de c. 480 a.C., la escultura fálica del heroon de Obulco, Porcuna, Jaén (González Navarrete, 1987, 121 s., n 19; Negueruela, 1990, 245 s.) y, más adelante, algunos exvotos ibéricos (Álvarez Ossorio, 1941, lám. 123, $\mathrm{n}^{\circ} 1662$, etc.). Todos estos elementos orgiásticos, asociados probablemente a mitos locales como ya intuyó Negueruela (1990, 245), debían tener un simbolismo cosmológico y escatológico, de la fecundidad y de la pervivencia en el Más Allá, pues beber vino da fuerzas, pero, al mismo tiempo, también produce la borrachera, un estado de trance que aproxima a ese Más Allá.

La proximidad de la pelike de Cabezo Lucero y el lékythos de Pozo Moro aportan luz sobre el rico y casi sorprendente ajuar que ofrecía el personaje enterrado en dicho monumento. En el decenio de c. 505 al 495 a.C. cabe incluir el lékythos, la kýlix y el Schnabelkanne de Pozo Moro (vid. supra) y la pelike de Cabezo Lucero, de c. 500-490 a.C., como, probablemente, el ánfora de La Albufereta (vid. supra), lo que añade precisión a la llegada y distribución de estas importacio- nes de muy alta calidad para las elites del mundo ibérico en el paso del siglo VI al V a.C., cuando tanto en el Egeo como en el Mediterráneo Occidental, el mundo helénico pugnaba con las culturas y pueblos orientales hasta alcanzar e1 480 a.C. la victoria de Salamina en Grecia y la de Himera en el Occidente.

En efecto, la pelike de Cabezo Lucero se inserta entre las cerámicas griegas aparecidas en el Sureste en la generación que va de fines del siglo VI a inicios del V a.C. (Shefton, 1995, 128, fig. 1), horizonte hasta ahora documentado por copas de forma $\mathrm{C}$, cuya presencia se extiende desde Cataluña (Padró y Sanmartí, 1992, 187) y Castellón (Sanmartí, 1976) y que se intensifica en el Sureste, como documentan los 10 ejemplares de Cabezo Lucero (Rouillard, 1993; Shefton, 1995, 128). Las importaciones de vasos áticos de relativa calidad de La Albufereta, Cabezo Lucero y Pozo Moro son relativamente suntuarias y reflejan un fuerte impulso del comercio emporitano tras la desaparición de Tartessos en la segunda mitad del siglo VI a.C. (Almagro-Gorbea, 1996, 77 s.; Torres, 2002, 385; Almagro-Gorbea et alii, 2008, 1075 s.), pues constituyen un tráfico comercial muy distinto del comercio arcaico de mediados del siglo VI a.C., caracterizado básicamente por el horizonte de copas 'jonias' y de arýballoi corintios y de Náucratis (Shefton, 1982, 354; Cabrera, 2000, 170 s.; Almagro-Gorbea, 2008, 590). En este mismo contexto se insertan en el Sureste otras importaciones de vasos de figuras rojas de calidad, como la copa $\mathrm{C}$ del Pintor del Louvre G 265 de Cabezo Lucero (Rouillard, 1991; 1993; Aranegui et alli, 1993, lám. 69; Domínguez Monedero y Sánchez, 2001, 43), de c. 480 a.C., y la copa de rojo 'coral' de Los Nietos (Trías, 1968, lám. 176,1), de fechas parecidas. Todos estos vasos parecen llegados vía Ampurias (Shefton, 1995, 129, 142), pues, aunque Shefton (1995, 148, n. 14bis) manifestó dudas sobre si los vasos de Pozo Moro habrían llegado a través del comercio ampuritano, quizás por la anómala riqueza y diversidad de objetos, ya que incluye un Schnabelkanne de Vulci (Graells, 2008b), la proximidad del lékythos de Pozo Moro y la pelike de Cabezo Lucero sugiere la llegada de ambos desde Sicilia en esos años del paso del siglo VI al V a.C. en unas circunstancias políticas que hicieron que la desembocadura del Bajo Segura jugara un papel esencial en esta nueva red comercial (Shefton, 1995, fig. 1), para desde ella, a través de Ilici y por el valle del Vinalopó ${ }^{8}$ alcanzar por Villena la vía Heraclea que pasaba por Fuente la Higuera y Almansa y en ella controlar el importante

8. Los hallazgos de fines del siglo VI e inicios del V a.C. parecen indicar que el Valle del Vinalopó a través de la Vía Heraclea ofrecía mejores condiciones que la vía del Valle del Segura que han propuesto Rouillard et alii $(2007,505)$ para alcanzar desde las costas del Sureste Andalucía Oriental. 
nudo de comunicaciones del Sureste de la la Meseta que representaba Pozo Moro como paso obligado hacia la Andalucía Oriental y el interior de la Meseta (Almagro-Gorbea, 1983, 182).

Esta política focense buscaba penetrar desde las costas del Sureste hacia el interior por vía terrestre para volver a alcanzar Andalucía tras la caída de Tartessos, esfuerzo que fue en aumento desde mediados del siglo $\mathrm{V}$ a.C. hasta la reacción púnica de la segunda mitad del siglo IV a.C. Por ello, estos escasos vasos áticos de cierta calidad de c. 500 a.C. documentan una nueva fase expansiva del comercio focense, que fue en aumento a lo largo del siglo $\mathrm{V}$ hasta alcanzar su auge en el IV a.C. Este comercio refleja, sin duda, fuertes intereses económicos, influjos culturales y presiones políticas, que penetraban desde el Sureste hacia Andalucía. Este proceso de helenización cultural y 'política' aún lo documentan mejor los signa equitum gentilicios ecuestres, con toda verosimilitud de carácter regio, que desde las costas levantinas alcanzaron Andalucía (Almagro-Gorbea y Lorrio, 2007). Su estilo es íberofocense, como el bronce del 'guerrero sacrificando un carnero' (Almagro-Gorbea y Fernández-Miranda (eds.), 1983, 148, no 107; Olmos, 1992, 146-147; Moneo, 2003, 375, fig. VI, $8, \mathrm{n}^{\circ} 1$ y portada) y como el resto de piezas jonio-ibéricas del 'estilo del rizo largo', fechadas a partir del 490 a.C. (Almagro-Gorbea et alli, 2004, 228 s.), entre las que se incluye el magnífico conjunto escultórico del heroon de Obulco, en Porcuna (Negueruela, 1991), labrado c. 480 a.C. o muy poco después, y algo posterior, c. 470-460 a.C., debe considerarse la Dama de Elche a juzgar por sus precisas características estilísticas.

Este cambio de estilo tan profundo y generalizado en la escultura ibérica refleja un cambio en la formación de los artesanos, pero, sobretodo, supone la llegada de nuevas concepciones ideológicas que dejan entrever un nuevo alineamiento político de las elites ibéricas, hecho que, en última instancia, explica el sorprendente cambio de orientación ideológica que se documenta en Pozo Moro (Almagro-Gorbea, 1983, 265). Su propietario utilizó artesanos fenicios para hacerse construir un magnífico monumento turriforme cargado de significado mítico oriental (López Pardo, 2006), pero ya se enterró con un ajuar que revela nuevas creencias de origen heleno, entre las que destacan mitos dionisiacos, dado el significado de la kýlix y el lékythos, y creencias en la heroización, como documenta el kouros del asa con leones del Schnabelkanne (López Pardo, 2006, 185, lám. 15,a-b; Graells, 2008b), pieza que, no por casualidad, también aparece en las sepulturas de los reges o Fürstern celtas del final del mundo hallstáttico, antes de su desaparición con los cambios socioideológicos que supuso la sociedad de La Tène.
En consecuencia, estas destacadas cerámicas griegas de c. 500 a.C. plantean la aparición en esas fechas de una nueva política 'comercial' helena dirigida hacia las regiones del Sureste de Iberia, con gran probabilidad llevada a cabo por los focenses desde Ampurias y en gran medida basada en exportaciones de cerámicas áticas de calidad, pero, sobretodo, en aportar artesanos para los monumentos funerarios que resaltaban el poder de las nuevas elites ibéricas y que plasmaban su ideología heroica, muy diferente de los mitos sacros orientalizantes que ofrece el monumento de Pozo Moro.

Este esfuerzo comercial, interpretado desde su perspectiva política, coincide prácticamente y no por casualidad con la fase álgida del enfrentamiento de Grecia con el Imperio Persa, heredero de las tradiciones del Oriente, en el decenio que va desde la sublevación Jonia (Herod. VI,17), cuya flota dirigió el focense Dionisio Foceo, quien acabó por organizar una base naval en Sicilia y piratear contra fenicios, cartagineses, etruscos y en un contexto histórico contemporáneo de la batalla de Maratón el 490 a.C. y no alejado de la de Salamina el 480 a.C., fecha esta última que también corresponde en Occidente al enfrentamiento y triunfo en Himera de los griegos sobre los púnicos. Suponer que en Iberia se debió producir una actividad bélica paralela es una hipótesis lógica ya planteada (Almagro-Gorbea y Lorrio, 2007), que esta nueva documentación parecen corroborar y precisar. Estas luchas debieron favorecer la expansión hacia Andalucía de las elites ibéricas, tal como evidencian los monumentos escultóricos de estilo jonio-ibérico, pero también algunos indicios lingüísticos y, quizás, la mitificación del enfrentamiento bélico en Gades protagonizado por uno de estos reyes ibéricos, Theron, rex Hispania Citerioris (Alvar, 1986; Almagro-Gorbea y Lorrio, 2005; 2007). En efecto, el episodio del ataque a Cádiz del rey Terón, transmitido por Macrobio en su Saturnalia (I,20,12), se puede relacionar con una penetración de elites ibéricas filohelenas desde el Sureste hacia la Andalucía central y occidental a inicios del siglo $\mathrm{V}$ a.C. A pesar del carácter mítico de la noticia, a la que quizás también aluda Justino $(44,5,1)$, ésta pudiera corresponder al enfrentamiento en Iberia entre griegos y púnicos a inicios del siglo V a.C., pues, según Macrobio, Terón era rey de la Hispania Citerior, es decir, que procedía de Andalucía Oriental, el Sureste o el Levante, como ya planteó J. Alvar (1986), quien ya supuso que pudo ser un régulo contestano, que, quizás con ayuda de los griegos del Levante de la Península Ibérica, pretendiera conquistar Cádiz, fracasando en el intento, aunque situó el hecho a mediados del siglo IV a.C.

Como confirmación de la importancia de esta crisis en torno al 500 a.C. podría relacionarse la destrucción del asentamiento fenicio de La Fonteta en los últimos 
años del siglo VI a.C. (Rouillard et alii, 2007, 29, 428, 505), que pudo ser 'sustituido' por la construcción de la factoría griega o filohelena de La Picola en esas fechas (Badie et alii, 2000), en las que también se inicia el pequeño oppidum ibérico de El Oral (Abad y Sala, 2001, 195 s.) y la necrópolis de Cabezo Lucero. Estas coincidencias parecen apuntar a que estos establecimientos estarían de algún modo relacionados en un proceso histórico más amplio, que, quizás por primera vez en la Historia, implicó a la lejana Iberia en los conflictos generales del Mediterráneo.

En esta política debió jugar un papel muy importante la introducción del consumo ritual del vino como elemento ideológico entre las elites ibéricas y, en paralelo, la asimilación de ideas que influirían en el imaginario ibérico y en sus concepciones cosmológicas, con nuevas visiones sobre la fecundidad y la perduración en el Más Allá a través de la heroización del antepasado fundador, como protector del clan familiar gentilicio y garante de la continuidad de su poder, clave de la nueva organización social, pues el Heros Ktistes pasó a sustituir en la ideología política las concepciones sacras de la monarquía de origen oriental basadas en el basileus kai hieros orientalizante (Almagro-Gorbea, 1996, 70 s.), como prueba la expansión de los citados signa equitum, que indica una nueva concepción del poder, que, verosímilmente, parece reflejar alianzas filohelenas (vid. supra).

En este contexto cabe señalar que la pelike de Cabezo Lucero parece ser, probablemente, la pieza más antigua hallada en la necrópolis y, además, es la pieza de más valor de la generación inicial o 'generación 0' en ella enterrada, por lo que quizás pudiera relacionarse con el personaje fundador del clan que pasó a enterrarse en dicho lugar, ya que corresponde al momento fundacional ${ }^{9}$. A esa misma generación o a una inmediata cabría atribuir también alguno de los monumentos aparecidos con esculturas zoomorfas (vid. infra), asociadas a golas de origen fenicio (Llobregat, 1993; Izquierdo, 2000, 144 s., fig. 65), que son semejantes a las aparecidas en La Fonteta (Dridi y Duboeuf, 2007), piezas que hay que interpretar como originarias de la necrópolis fenicia de dicho yacimiento. Sin embargo, en Cabezo Lucero estas golas se asocian ya a molduras

9. En este sentido, hay que valorar que este vaso griego parece anterior a la urna de tipo 'Cruz del Negro' (Aranegui et alii, 1993, 241 s., fig. 78), de forma evolucionada (Torres, 2008, 647 s.), asociada a una grebas de guerrero (Farnié y Quesada, 2005), un elemento que debieron difundir los focenses (Almagro-Gorbea, 2009, 162). Esta sepultura de Cabezo Lucero queda datada por un lékythos del Grupo de Haimon de c. 490475 a.C. (Aranegui et alii, 1993, 242, lám. 66,a-c) y ofrece una mezcla de elementos de origen fenicio y focense que hace pensar en el caso de Pozo Moro (Almagro-Gorbea, 1983). con ovas de tipo jonio (Izquierdo, 2000, fig. 63) y a estelas rematadas en una palmeta arcaica (Izquierdo, 2000, fig. 65), lo que denota el mismo cambio de influjos comerciales asociados a profundos cambios estilísticos que refleja el ajuar de Pozo Moro respecto al monumento orientalizante (Almagro-Gorbea, 1983).

En la plataforma B aparecieron diversos fragmentos de escultura de un toro (Llobregat, 1993, 76, lám. $11,38-39$ y $41-44$ ), cimacios con ovas y dardos (Llobregat, 1993, 77, lám. 42), una cornisa de gola (Llobregat, 1993, 77, fig. A, lám. 40) y una estela en forma de palmeta (Llobregat, 1993, 76, lám. 41). En la plataforma $\mathrm{E}$ aparecieron numerosos fragmentos de escultura de toro (Llobregat, 1993, $78 \mathrm{~s}$.) y la palmeta de una estela (Llobregat, 1993, 78, lám. 47). En la plataforma $\mathrm{G}$ aparecieron diversos fragmentos de toro (Llobregat, 1993, 79 s., lám. 50 y 53), una moldura de gola (Llobregat, 1993, 79, lám. 51) y un posible cimacio con ovas (Llobregat, 1993, 79, lám. 52). En la plataforma $\mathrm{P}$ se hallaron nuevos fragmentos de toro y de león (Llobregat, 1993, 59 y 61-62), una gola egipcia (Llobregat, 1993, 81) y otra posible palmeta (Llobregat, 1993, 81, lám. 63). Además, en las cuadrículas 25 y 26, de donde precisamente procede la pelíke de Eucharides, apareció un relieve muy fragmentado con un ave rapaz, una palmeta y, al parecer, un bóvido (Llobregat, 1993, 80, lám. 54-58), elementos que cabría atribuir hipotéticamente a esta tumba del Heros Ktístes de al población enterrada en Cabezo Lucero.

Las posibles estelas rematadas en una palmeta arcaica tienen su mejor paralelo en la Ilici arcaica (Izquierdo, 2000, fig. 70,1), mientras que las esculturas zoomorfas sobre monumentos con golas y molduras de tipo jonio corresponden a monumentos de tipo 'Montforte del Cid', caracterizados por una gran gola con molduras jonias sobre la que se erguía la estatua de un toro del arcaismo final, el cual, por razones estilísticas y a falta de contexto arqueológico, datamos en torno al 500 a.C. (Almagro-Gorbea y Ramos, 1986). Esta fecha no es una coincidencia. La identificación de esta pelíke atribuida al Pintor de Eucharides en Cabezo Lucero ofrece nueva luz sobre este yacimiento y ayuda a comprender con más detalle la política expansiva joniofocense apoyada en una agresiva actividad comercial en los años cruciales del enfrentamiento de Grecia con Persia y con Cartago. En esos años los focenses de Occidente desarrollaron esta 'política expansiva' con gran eficacia, de la que aún queda mucho por saber, pero que contribuyó en Iberia a transformar las tradiciones orientalizantes de la colonización fenicia y a dar inicio a una paulatina y progresiva helenización.

Este es el significado que parecen tener los escasos fragmentos conservados de la pelíke del Pintor de Eucharides hallados en Cabezo Lucero, que prueban una vez más cómo siempre es útil revisar los hallazgos, 
por modestos que parezcan, pues pueden dar sorpresas que ayuden a comprender mejor el yacimiento de donde proceden y, en ocasiones como ésta, a facilitar su adecuada comprensión en su contexto histórico.

\author{
Prof. Dr. Martín Almagro-Gorbea \\ Real Academia de la Historia \\ c/ León 21 \\ 28014 Madrid \\ anticuario@rah.es
}

\section{BIBLIOGRAFÍA}

Abad, L. y SAla, F., 2001: Poblamiento ibérico en el Bajo Segura. El Oral (II) y La Escuera, Biblioteca Archaeologica Hispana 12, Madrid.

Almagro-Gorbea, M., 1962: «Nuevas tumbas halladas en la Necrópolis de Ampurias», Ampurias, 24, 225-238.

Almagro-Gorbea, M., 1983: «Pozo Moro. El monumento orientalizante, su contexto socio-cultural y sus paralelos en la arquitectura funeraria ibérica», Madrider Mitteilungen, 24, 1983, 177-392.

Almagro-Gorbea, 1996: Ideología y Poder en Tartessos y el mundo ibérico. Discurso de ingreso en la Real Academia de la Historia, Madrid.

Almagro-Gorbea, M., 2008: «Cerámica griega», en M. Almagro-Gorbea, (ed.), La Necrópolis de Medellín, II. Estudio de los hallazgos, Biblioteca Archaeologica Hispana 26-2, 577-592, Madrid.

Almagro-Gorbea, M. (ed.), 2008: La Necrópolis de Medellín, III. El marco histórico de Medellín-Conisturgis, Biblioteca Archaeologica Hispana 26-3, Madrid.

Almagro-Gorbea, 2009: «Guerra y armamento de los griegos focenses», en M. Almagro-Gorbea (coord.), Prehistoria y Antigüedad, en H. O'Donnell (ed.), Historia Militar de España, I, 160-164, Madrid.

Almagro-Gorbea, M., 2009: «El kýlix de figuras rojas arcaicas de Pozo Moro (Albacete)», Cuadernos de Prehistoria y Arqueología Castellonense, 27, 63-81.

Almagro-Gorbea, M., Casado, D., Fontes, F., Mederos, A. y Torres, M., 2004: Antigüedades Españolas, I. Prehistoria (Catálogo del Gabinete de Antigüedades de la Real Academia de la Historia), Madrid.

Almagro-Gorbea, M. y Fernández-Miranda, M. (eds.), 1983: Los iberos (catálogo de exposición), Madrid.

Almagro-Gorbea, M. y Lorrio, A., 2007: «El signum equitum ibérico del Museo de Cuenca y los bronces ibéricos tipo «Jinete de la Bastida»», en J. M. Millán y C. RodRíGuez Ruza (eds.), Arqueología de Castilla-La Mancha, Actas de las I Jornadas (Cuenca, 2005), 17-51, Cuenca.

Almagro-Gorbea, M., Lorrio, A., Mederos, A. y Torres, M., 2008: La Necrópolis de Medellín, III. Interpretación de los hallazgos, Biblioteca Archaeologica Hispana 263, 577-592, Madrid.

Almagro-Gorbea, M. y Ramos, R., 1986: «El monumento ibérico de Montforte del Cid (Alicante)», Lucentum, V, 45-63.

Alvar, J., 1986: «Theron, rex Hispaniae Citeriors (Macr., Sat. I, 20, 12)», Gerion, 4, 161-175.
Alvarez-Ossorio, F., 1941: Museo Arqueológico Nacional. Catálogo de lso exvotos de bronce ibéricos, Madrid.

Aranegui, C., Jodin, A., Llobregat, E., Rouillard, P. y Uroz, J., 1993: Nécropole ibérique de Cabezo Lucero. Guardamar del Segura, Alicante, Madrid-Alicante.

Arias P. E. y HiRmER, M., 1960: Tausend Jahre griechische Vasen, München.

Badie, A., Gailledrat, E., Moret, P., Rouillard, P., SÁnCHez, M. J. y Sillières, P., 2000: Le site antique de La Picola à Santa Pola, Alicante, Espagne, Paris.

BeAzley, J. D., 1912: «The Master of the Eucharides-Stamnos in Copenhagen», Annual of the British School of Athens, 18, 217-233.

Beazley, J. D., 1913: «The Master of the Stroganoff Nikoxenos Vase», The Annual of the British School of Athens, 19, 229-247.

Beazley, J. D., 1928: Attic Black-figure. A sketch, London.

Beazley, J. D., 1951: The Developpment of Attic Black-figure, Los Angeles.

Beazley, J. D., 1956: Attic Black-figure Vase Painters, Oxford.

Beazley, J. D., 1963: Attic Red-figure Vase Painters'2, Oxford.

Beazley, J. D., 1971: Paralipomena. Additions to Attic Black-figure Vase Painters and to Attic Red-figure Vase Painters $^{2}$, Oxford.

Beazley, J. D., 1982: Beazley Addenda. Additional References to Attic Black-figure Vase Painters, Attic Red-figure Vase Painters ${ }^{2}$ and Paralipomena, en Th. H. Carpenter (ed.), Oxford.

BeCKer, R.-M., 1977: Formen attischer Peliken von der Pionier-Gruppe bis zum Beginn der Frühklassik, Tesis Doctoral de la Universidad de Tübingen, Tübingen.

BenNDORF, O., 1883: Griechische und Sicilische Vasenbilder, Berlin.

Berge, J., 1980: «Attic Black-Figure Pelike», en W. G. Moon (ed.), Greek Vase-Painters in Midwestern Collections, 140-141, Chicago.

Boardman, J., 1975: Athenian Red Figure Vases. The Archaic Period. A. Handbook, London.

Bodiou, L., Frère, D. y MeHL, V., 2008: Parfums et odeurs dans l'Antiquité, Rennes.

Bothmer, D. von, 1951: «Attic Black-figured Pelikai», Journal of Hellenic Studies, 71, 40-47.

Bothmer, D. von, 1979: «Recensión a R.-M. Becker, 1977», American Journal of Aracheolgy, 83, 361-362.

BruHL, A., 1953: Liber Pater. Origine et expansion du culte dionysiaque à Rome et dans le monde romain, Paris.

Cabrera, P., 2000: «El comercio jonio arcaico en la Península Ibérica», en P. Cabrera y M. Santos Retolaza (eds.), Ceràmiques jònies d'època arcaica. Centres de producció i comercialització al Mediterrani Occidental, Monografies Emporitanes 11, 165-176, Barcelona.

Cabrera, P. y Santos Retolaza, M. (eds.), 2000: Ceràmiques jònies d'època arcaica. Centres de producció $i$ comercialització al Mediterrani Occidental, Monografies Emporitanes 11, Barcelona.

CArpenter, Th. H. y Mannack, Th. 2000: Summary Guide to Corpus Vasorum Antiquorum ${ }^{2}$, Oxford. 
CoHen, B., 1978: Attic Bilingual Vases and Their Painters, New York.

Daremberg, Ch. y Saglio, E., 1877: Dictionnaire des Antiquités Grecques et Romaines, I/1, Paris.

Deonna, W., 1953: Le symbolisme de l'acrobatie antique (Collection Latomus 9), Bruxelles.

Domínguez Monedero, A. J. y Sánchez, C. 2001: Greek Pottery from the Iberian Peninsula. Archaic and Classical Periods, Leiden.

Dridi, H. y Duboeuf, P., 2007: «Les éléments architecturaux antiques réemployés dans La Rabita d'époque califal», en P. Rouillard, E. Gailledrat y F. Sala (eds.), 2007, L'établissement protohistorique de La Fonteta (fin VIIIe - fin Ve siècle av. J.-C.), 155-183, Madrid.

Dusenbery, E. B., 1964a: «The South Nekropolis of Samotrace», Archaeology, 17, 185-192.

Dusenbery, E. B., 1964b: The Nekropoleis. Samotrace 11, Princeton, N.J.

FARniÉ C. y Quesada, F., 2005: Espadas de hierro, grebas de bronce. Símbolos de poder e instrumentos de guerra a comienzos de la Edad del Hierro en la Península Ibérica, Murcia.

Fless, F., 2000: Rotfigurige Keramik als Haldelware. Erweb und Gebrauch attischer Vasen im mediterranen und pontischen Raum wärend des 4. Jhs. V. Chr., Internationale Archäologie 71, Rahden-Wetf.

García Bellido, A., 1948: Hispania Graeca, I-II, Barcelona.

García Martín, J. M. y Llopis, T., 1995: «Una cràtera de columnes de figures negres a la Necròpolis de l'Albufereta d'Alacant», XXIII Congreso Nacional de Arqueología, 473-480, Elche.

González Navarrete, J., 1987: Escultura ibérica de Cerrillo Blanco. Porcuna, Jaén, Jaén.

González Prats, G. y Ruiz Segura, E., 2000: El yacimiento fenicio de La Fonteta (Guardamar de Segura, Alicante), Valencia.

Graells, R., 2008a: Análisis de las manifestaciones funerarias en Catalunya durante los ss. VII y VI aC. Sociedad y cultura material: la asimilación de estímulos mediterráneos, Tesis Doctoral, Universidad de Lérida, Lérida.

Graells, R., 2008b: «Vasos de bronce 'a kouroi’ en el Occidente arcaico a la luz de un nuevo ejemplar procedente de Cuenca», Archivo Español de Arqueología 81, 201212.

Haspel, C. H. E., 1936: Attic Black-figured Lekythoi, Paris.

HuBER, K., 1999: Le ceramica attiche a figure rosse (Gravisca. Scavi nel santuario greco, 6). Bari.

IACOBAZZI, B., 2004: Le ceramica attiche a figure nere I-II (Gravisca. Scavi nel santuario greco, 5,1-2). Bari.

IzQuiERdo, I., 2000: Monumentos funerarios ibéricos: los pilares-estela, Serie de Trabajos Varios 98, Valencia.

Johnson, F. P., 1943: «Black-figure Pottery at Chicago», American Journal of Archaeology, 47, 385-402.

Karouzou, S., 1971: «Une tombe de Tanagra», Bulletin de Correspondance Hellénique, 85, 109-145.

LABorde, A. de, 1813: Collection de vases grecs de M. de Le Comte de Lamberg, Paris.

Lehmann, K., 1966: Samothrace. A Guide to the Excavations and the Museum ${ }^{3}$, New York.
López PArdo, F., 2006: La Torre de las Ánimas, Anejos de Gerión 10, Madrid.

Lorrio, A. y Almagro-Gorbea, M., 2005: «Signa equitum en el mundo ibérico. Los bronces tipo «Jinete de La Bastida» y el inicio de la aristocracia ecuestre ibérica», $L u$ centum, 23-24, 37-60.

Llobregat, E., 1993: «Arquitectura y escultura en la necrópolis de Cabezo Lucero», en C. Aranegui, A. Jodin, E. Llobregat, P. Rouillard y J. Uroz, 1993, Nécropole ibérique de Cabezo Lucero. Guardamar del Segura, Alicante, 69-85, Madrid-Alicante.

Maffre, J.-L., 2010: «Les images grecques des marchands de parfum», Dossier d'Archéologie, 337, 42-43.

Mata, C. y Burriel, J. M., 2000: «Importaciones de los siglos VI-V aC en el centro y norte del País Valenciano», en P. Cabrera y M. Santos Retolaza (eds.), Ceràmiques jònies d'època arcaica. Centres de producció $i$ comercialització al Mediterrani Occidental, Monografies Emporitanes 11, 233-254, Barcelona.

Mingazzini, P., 1930: Vasi de la collezione Castellani, Catálogo, Roma.

Moneo, T., 2003: Religio Iberica. Santuarios, ritos y divinidades (siglos VII-I a.C.), Bibliotheca Archaeologica Hispana 20, Madrid.

Negueruela, I., 1990: Los monumentos escultóricos ibéricos del Cerrillo Blanco de Porcuna (Jaén), Madrid.

Noble, J. V., 1965: The Techniques of Painted Attic Pottery, New York.

Olmos, R., 1977: El Sileno Simposiasta de Capilla (Badajoz). Trabajos de Prehistoria, 34, 371-388.

Olmos, R. (ed.), 1992: La sociedad ibérica a través de la imagen, catálogo de exposición, Madrid.

Olmos, R. y SÁnchez, C., 1995: «Usos e ideología del vino en las imágenes de la Hispania prerromana», en S. CELESTino (ed.), Arqueología del vino. Los orígenes del vino en Occidente, 105-136, Jerez de la Frontera.

Padró, J. y SAnMARTí, E., 1992: «Areas geográficas de las etnias prerromanas de Cataluña», en M. Almagro-GorbeA y G. Ruiz Zapatero (eds), Paleoetnologia de la Península Ibérica, Madrid-1989, Complutm, 2-3, 185-194.

Pharmakowsky, B., 1912: «Russland», Archäologische Anzeiger, 324-328.

Price, T.H., 1971: «'To be or not to be' on an Attic BlackFigure Pelike», American Journal of Archaeology, 75, 431-434, láms. 93-94.

Richter, G. M. y Milne, M. J., 1935: Shapes and names of Athenians Vases, New York.

Robertson, M., 1962: «A Fragment by the Nikoxenos Painer», American Journal of Archaeology, 66: 311-312, lám. 83 .

ROBERTSON, M., 1992: The art of vase-painting in classical Athens, Cambridge.

RouIllaRd, P., 1991: Les grecs et la péninsule Ibèrique du $V_{I I I}^{e}$ au IV siècles avant Jésus-Christ, Paris.

Rouillard, P., 1993: «Le vase grec à Cabezo Lucero», en C. Aranegui, A. Jodin, E. Llobregat, P. Rouillard y J. Uroz, 1993: Nécropole ibérique de Cabezo Lucero. Guardamar del Segura, Alicante, 87-94, Madrid-Alicante. 
Rouillard, P., 1997: Antiquités de l'Espagne, Musée du Louvre. Département des Antiquités Orientales, Paris.

Rouillard, P., Gailledrat, E. y Sala, F. (eds.), 2007: L'établissement protohistorique de La Fonteta (fin VIIIe - fin Ve siècle av. J.-C.), Madrid.

SANMARTí, E., 1976: «Cerámicas de importación ática de El Puig (Benicarló, Castellón)», Cuadernos de Prehistoria y Arqueología Castellonense, 3, 219-28.

Shapiro, H. A., 1997: «Correlating Shape and Subject: The Case of the Archaic Pelike», en J. H. OAKley, W. D. E. Coulson y O. Palagia (eds.), Athenian Potters and Peinters (Oxbow Monograph 67), Exeter: 63-70.

Shefton, B. B., 1982: "Greeks and Greek Imports in the South of de Iberian Peninsula», en H.-G- Niemeyer, Phönizier im Westen, Madrider Beiträge 8, 337-370, Mainz.

Shefton, B.B. 1990: «Intervention», en La Magna Grecia e il Lontano Occidente», Atti $29^{\circ}$ Convegno di Studi sulla Magna Grecia, (Taranto-1989), 189-200, Taranto.

Shefton, B. B., 1995: "Greeks Imports at the Extremities of the Mediterranean, West and East: Reflections on the Case of Iberia in the Fifth Century BC», en B. Cunliffe y S. Keay (eds), Social Complexity and the Development of Towns in Iberia. From the Copper Age to the Second
Century AD, Proceedings of the British Academy 86, 127-155, Oxford.

Smith, A. C., 2007: Corpus Vasorum Antiquorum. Reading Museum Service 1, Great Britain 2, Oxford.

StÄHLER, K., 1967: Eine Unbekannte Pelike des Eucharidesmalers im Archäologischen Museum der Universität Münster, Köln.

Torres, M., 2002: Tartessos, Bibliotheca Archaeologica Hispana 14, Madrid.

Torres, M., 2008: «Urnas de tipo Cruz del Negro», en M. Almagro-Gorbea (ed.), La Necrópolis de Medellín, II. Estudio de los hallazgos, Biblioteca Archaeologica Hispana 26-2, 631-654, Madrid.

TRÍAs, G., 1969: Cerámicas griegas de la Península Ibérica, I-II, Valencia.

Villanueva, M. C., 1987: «Images de Dionysos et de son cortège dans la céramique grecque du IVè. s. en provenance de la Péninsule Ibérique», Grecs et ibères au IVe siècle avant Jésus-Christ. Commerce et iconographie, Revue d'Études Anciennes, 89,3-4), 297-317.

Werner, I., 2005: Dionisos in Etruria. The Ivy Leaf Group, Acta Instituti Romani Regni Sueciae, $4^{\circ}, 58$, Stockholm. 